\title{
Actor-Network Theory and IS Research: Current Status and Future Prospects
}

\author{
G. Walsham
}

The Judge Institute of Management Studies

University of Cambridge

Cambridge CB2 1AG, England

E-mail: gw10@eng.cam.ac.uk

\begin{abstract}
An increasing interest is being shown, not least by IS researchers, in the socio-technical approach known as actor-network theory. The purpose of this paper is to assess the current and potential future contribution of the theory to IS research. A brief review of key concepts of the theory is given, some IS literature which uses the theory is described, and significant criticisms of the theory are examined in some detail. Finally, implications are drawn on the potential value of the theory for IS research in the future, with the broad conclusion being that it has much to offer in both theoretical and methodological terms.
\end{abstract}

\section{INTRODUCTION}

The initial development and application of actor-network theory was concerned with the sociology of science and was pioneered at the École des Mines in Paris by Michel Callon (1986) and Bruno Latour (1987). Later work has included a focus on technology (Latour 1996a) and information technology (Latour 1996b) and, in these areas, the theory can be considered to be a development of one strand of the wider school of thought on the social construction of technology (Bijker, Hughes and Pinch 1987). Actor-network theory is concerned with investigating the social and the technical taken together or, putting it another way, with the creation and maintenance of coex- 
tensive networks of human and nonhuman elements which, in the case of information technology, include people, organizations, software, computer and communications hardware, and infrastructure standards.

An interest in viewing information systems from the perspective of socio-technical theory has a long pedigree in information systems research, and in IFIP Working Group 8.2, particularly associated in its early days with the work of Mumford (1981) on participative design. However, this approach treated the social and the technical as relatively separate elements, while acknowledging the importance of addressing both elements seriously. In contrast, actor-network theory treats the social and the technical as inseparable, and indeed argues that people and artefacts should be analyzed with the same conceptual apparatus. This point will be discussed in further detail later in the paper, but Latour (1996b, p. 302) illustrates the rationale for symmetric treatment in the following observation on the relationship between "technical" computer systems and "social" organizations:

It is no longer clear if a computer system is a limited form of organization or if an organization is an expanded form of computer system. Not because, as in the engineering dreams and the sociological nightmares, complete rationalization would have taken place, but because, on the opposite, the two monstrous hybrids are now coextensive.

This description of an aspect of the contemporary world, radically different from the world of computing in the 1970s which gave rise to socio-technical design, suggests a reason for the emergence of actor-network theory, and the rationale as to why it may offer an important contribution to the IS field. We need new methodological and theoretical devices to enable us to think about hybrids of people and information technology: pilots and computer-controlled planes; computers and people playing chess; the Internet; medical diagnosis systems; electronic tagging for prisoners; robots in surgery. The symbolic boundary between people and information technology is in a constant state of flux across a wide spectrum of contemporary work and leisure activities, and actor-network theory offers one way to investigate the issues and dilemmas in this new world.

The purpose of this paper is to review the current status of actor-network theory in IS research, to critically consider the theory's advantages and disadvantages, and thus to offer some views on its relevance and importance to future IS research. In the next section, a brief introduction to the theory is given, mainly for the benefit of those readers who are unfamiliar with its ideas and concepts. This is followed by a review of the literature to date on the application of the theory in the IS field. Next, criticisms of the theory are examined, and the relevance of these criticisms to IS research is discussed. The final section draws together the previous material by offering a personal view of the utility of the theory for IS research. 


\section{SOME KEY CONCEPTS IN ACTOR-NETWORK THEORY}

A first point to note is that actor-network theory is not a stable and unified body of knowledge which can be drawn on by researchers, since its developers frequently revise or extend elements of the theory. Indeed, the author of this paper recently attended a seminar by Latour in which he expressed the view that he would like to "recall" the theory like a defective car. However, the theory also has its strengths, and this section will highlight some key elements of the theory which have remained relatively stable over the last decade or so of its development and use (see Law (1992) for a fuller description). Table 1 provides a brief summary of key concepts in the theory.

Table 1 Summary of Some Key Concepts in Actor-Network Theory.

\begin{tabular}{ll}
\hline Concept & Description \\
\hline Actor (or actant) & $\begin{array}{l}\text { Both human beings and nonhuman actors such } \\
\text { as technological artefacts } \\
\text { Heterogeneous network of aligned interests, } \\
\text { including people, organizations and standards } \\
\text { Creating a body of allies, human and non-hu- } \\
\text { man, through a process of translating their inter- } \\
\text { ests to be aligned with the actor-network } \\
\text { translation }\end{array}$ \\
$\begin{array}{l}\text { Delegates are actors who "stand in and speak } \\
\text { for" particular viewpoints which have been in- } \\
\text { seribed in them, e.g., software as frozen organi- }\end{array}$ \\
$\begin{array}{l}\text { zational discourse } \\
\text { The degree to which it is subsequently impossi- } \\
\text { ble to go back to a point where alternative possi- } \\
\text { bilities exist } \\
\text { A frozen network element, often with properties } \\
\text { of irreversibility }\end{array}$ \\
Black box & $\begin{array}{l}\text { Network element with strong properties of irre- } \\
\text { versibility, and effects which transcend time and } \\
\text { place, e.g., software standards }\end{array}$ \\
\hline
\end{tabular}

Actor-network theory examines the motivations and actions of groups of actors who form elements, linked by associations, of heterogeneous networks of aligned interests. A key feature of the theory is that actors are taken to include both human beings and nonhuman actors such as technological artefacts. This perspective has created considerable controversy; for example, Collins and Yearley (1992a) argue that 
the failure of the theory to make a distinction between human action and the behavior of things is an abdication of human responsibility. Callon and Latour (1992) respond that they do not deny differences, but that they refuse to consider them a priori and to hierarchy them once and for all into humans and nonhumans. They prefer to treat them all as "actants" who form a part of hybrid networks. Collins and Yearley (1992b) say that they "now concede that the term 'actant' does make a difference," but they continue to argue that the differences between actors and actants are vital. We will return to this important debate again later in the paper.

A major empirical focus of the theory when applied in particular contexts is to try to trace and explain the processes whereby relatively stable networks of aligned interests are created and maintained, or alternatively to examine why such networks fail to establish themselves. Successful networks of aligned interests are created through the enrolment of a sufficient body of allies, and the translation of their interests so that they are willing to participate in particular ways of thinking and acting which maintain the network. Bloomfield et al. (1992) point out that the analysis of the various stratagems employed, such as the use of persuasive rhetoric, to construct and maintain network allegiances draws much from Machiavelli. However, they note the addition in actor-network theory that nonhuman resources, such as a graph in a scientific paper, can be used to "stand in or speak for," or be delegates for, particular viewpoints or truth-statements which help to maintain a particular network of alliances. Bowker and Star (1994, p. 187) make a similar representational point with respect to computer systems and software:

Modern information technologies embed and inscribe work in ways that are important for policy-makers, but which are often difficult to see... arguments, decisions and uncertainties and processual nature of decisionmaking are hidden away inside a piece of technology or in a complex representation. Thus values, opinions, and rhetoric are frozen into codes, electronic thresholds and computer applications. Extending Marx, then, we can say that in many ways, software is frozen organizational discourse.

The idea of software as frozen discourse is an example of an inscription which resists change and displays properties of irreversibility. Callon (1991) says that the degree of irreversibility of a particular element of a network depends on the extent to which it is subsequently impossible to go back to a point where alternative possibilities exist, and the extent to which the particular frozen element, or black box, shapes and determines subsequent inscriptions. Actor-network theory uses the term immutable mobiles to describe network elements which display strong properties of irreversibility and are mobile across time and space; various software standards provide illustrations of immutable mobiles.

It is important to note that actor-network theory, in contrast to many social theories, is both a theory and methodology combined. In other words, it not only provides theoretical concepts as ways of viewing elements in the real world, it also suggests that it is exactly these elements which need to be traced in empirical work. So, the researcher is led to investigate and document network elements, both human and 
nonhuman, processes of translation and inscription, the creation of black boxes or immutable mobiles, and the degree of stability and irreversibility of networks and their elements. This is, of course, no small task for a complex network, and we will return to this point again in our later critical discussion of the theory.

\section{ACTOR-NETWORK THEORY IN THE IS LITERATURE}

Actor-network theory has become much more widely known in recent years, and an increasing number of IS researchers are making explicit use of the theory in their work. Although there is considerable variety in these applications, all the authors cited below are supportive of the view that the theory offers new concepts and ideas for the understanding of the socio-technical nature of information systems. The purpose of this section is to critically review some of this work, and to examine the ways in which actor-network theory contributed to the authors' methodology or analysis.

Bloomfield et (1992) provide an interesting case study of the development of a particular set of resource management information systems in the UK National Health Service, and they use concepts from actor-network theory to analyze their findings. They point out how the actor-network approach does not privilege either social aspects or technology, which reflects the situation in the case study itself where arguments about social structures and technology are interwoven within the discourse of actors as they attempt to persuade others to align with their own interests. The paper emphasizes the interpretative flexibility of information technology and systems, in the sense that seemingly similar systems result in radically different outcomes in different locations, due to the specific processes of translation and network-building which took place. They argue against the view of technology as a given, but instead illustrate how the boundary between the technical and the social, and the relationship between them, is the subject of ongoing struggles and trials of strength in creating the facts. A related discussion of boundary disputes between the technical and the social, illustrated by cases in the NHS and in an IT systems planning consortium, is given in Bloomfield and Vurdubakis (1994). These two papers provide valuable examples of the use of actor-network theory for case analysis, although it is not clear from the papers whether the theory was used as a methodology for the empirical work as well as for analytical purposes.

A second set of illustrative applications of actor-network theory in IS research is contained in the proceedings of the preceding IFIP Working Group 8.2 Conference in Cambridge (Orlikowski et al. 1996). In addition to a short plenary paper by Latour (1996b), five other papers explicitly use aspects of the theory. Boland and Schultze (1996) adopt the vocabulary of the theory to describe activity based costing as an accounting technology that has been made true, and has been established as a widespread practice, through a process of translation in which allies have been enrolled, black boxes have been constructed to enshrine the approach, and arguments have been 
built up into many layered defenses against adherents of traditional cost accounting techniques. The authors undermine the certainties of this fact construction process by telling a different story, or anti-narrative, where the merits of the two techniques are reversed. They conclude that we need to allow multiple inscriptions and representations of organizational work involving information technology. Bowker, Timmermans and Star (1996) pursue a similar theme of the inscription of work, using an empirical example of a classification scheme for understanding nursing work. They describe how such a classification scheme can be considered to be a political actor, and how the processes in its creation are difficult to retrace once it has been blackboxed.

Two further empirical papers using actor-network theory were presented at the conference cited above. Monteiro and Hanseth (1996) focus on the role of standards, particularly those embedded in infrastructures, in prescribing and proscribing forms of interaction with information technology. Their examples involve EDI systems in the Norwegian health sector, and concern the definition of a message standard for identifying a drug prescription and one for exchanging test results. In both cases, they illustrate the processes of translation and inscription which were taking place, and they contrast the relative successes of the network-building in the two cases. Vidgen and McMaster (1996) describe a case study of an innovative car parking system which was both an information system and an access control point. They carry out a stakeholder analysis of both human and nonhuman interests, and describe how the attempted translation of these interests into the black box of fact was not achieved due to weaknesses in the network of associations between stakeholders. The two papers described in this paragraph are interesting illustrations of the application of actornetwork theory in IS research, although their laudable emphasis on explaining the technology seemed to be at the expense of explaining the social interactions in some cases.

To conclude this brief literature review, mention is now made of four other papers, illustrating different areas of application of the concepts in actor-network theory to IT-related areas. Bowers (1992) discusses computer-mediated communication, and notes that the mixture between the human and the nonhuman is being named and welcomed here. He argues, following Latour and others, that if we are to take computer technology seriously, then we will have to abandon innocent humanism in favor of the world of cyborg politics (Haraway 1991). Kavanagh and Araujo (1995) discuss the nature and social construction of time, using actor-network theory as a basis for examining field material from a longitudinal study of the replacement of a control system in a pharmaceutical plant. Hine (1995) describes an information system for botanical plant categorization, and argues that the system came to represent both the plants being described and the taxonomists doing the work. The black-boxing of the taxonomy arose as a result of the social, political, organizational and scientific work that went into the project. Finally, Walsham and Sahay (1996) describe the attempt at the creation of a network of aligned interests for the development and use of GIS for district-level administration in India. The GIS technology inscribed interests of 
its Western developers, and the paper describes how and why the attempts at translation and alignment of the interests of local-level administrators were a relative failure. In contrast to the comment at the end of the preceding paragraph, this latter paper contains a reasonable degree of detail on aspects of social interaction, but perhaps at the expense of a detailed description of the technological inscriptions.

\section{CRITICAL APPRAISALS OF THE THEORY}

Any new social theory which receives significant attention tends also to attract criticism, and actor-network theory is no exception to this. It is important that IS researchers who are thinking of using the theory should be aware of these criticisms, and should thus be able to generate an informed view of the usefulness and limitations of the theory in their own work. As far as this author is aware, no similar critical appraisal is available in the IS literature to date. Four broad strands of critique will be considered in this section. In each case, the nature of the criticism will be articulated, responses made by proponents of actor-network theory will be considered, and a personal view on the relevance of this debate for IS research will be offered.

\subsection{Limited Analysis of Social Structures}

A major strand of criticism of actor-network theory is that it addresses the local and contingent, but that it pays little attention to broader social structures which influence the local. Reed (1995) provides an example of such a critique. He focuses on the description of actor-network theory in Law (1994) and argues that the theory engages in a form of analysis that concentrates on how things "get done" to the virtual exclusion of the various ways in which institutionalized structures shape and modify the process of social interaction and the socio-material practices through which it is accomplished. [Reed 1995, p. 332]

Habers (1995, p. 273) makes a similar point, when reviewing Latour (1993), that Latour provides an "asymmetrical reading of the mediation process, which is overly oriented towards the contribution of things to the production of the social order, almost neglecting the reverse, that is, the "sociality' of the stability of things."

What do proponents of the theory say in response to these criticisms? Latour tackles the issue head-on, saying that

Network analysis and field work have been criticised for giving interesting demonstrations of local contingencies without being able to take into account the "social structures" which influence the course of local history. Yet...the macro-structure of society is made of the same stuff as the microstructure. [Latour 1991, p. 118] 
Latour goes on to say that it is possible to use the actor-network methodology to move between levels of analysis and that macro-structures can thus be investigated with the same methodological tools as micro-structures. These are bold claims and it is clear that organizational theorists such as Reed remained unconvinced that the substantial prior work of sociologists on the nature and influence of social structures on microevents and processes can be dismissed so readily. Law (1991) also defends actornetwork theory against the above criticism in noting that social structures do not simply reside in the actions of people or in "memory traces" (Giddens 1984), but in a network of heterogeneous material arrangements. Yes, but this argument can be turned around, to note that we need to analyze not just material arrangements but also the memory traces and their implicit social structures.

The author of this paper shares some of the concerns expressed in the critique above, and is not convinced by the exclusivity arguments of the proponents of actornetwork theory. One approach then for IS researchers is to combine the methodological approach and conceptual ideas of actor-network theory with insights and analyses drawn from theories of social structure. The work of Giddens was briefly referenced above, and structuration theory (Giddens 1984) and his later work linking levels of analysis from the individual to the global (Giddens 1990, 1991) offer sophisticated models of social action and structure at multiple levels. A major limitation of Giddens' work, from the perspective of an IS researcher, is that it offers little in the way of methodological guidelines, and that the material world of technology is not treated in any depth. A combination of this work with the methodology and concepts of actor-network theory would offer more than either one. Giddens (1984) argued that he did not set out to "wield a methodological scalpel" and he would thus probably be comfortable with this theoretical eclecticism. It is unlikely that the proponents of actor-network theory would accept a similar compromise, but their own theory recognizes the way in which ideas are translated by others and emerge in a different form, so at least the suggestions here would be compatible with that analysis.

\subsection{An Amoral Stance}

A second broad area of criticism of social constructivism in general, and actor-network theory in particular, concerns its stance on moral and political issues. This criticism was most forcefully articulated by Winner (1993). In this paper, Winner notes positive aspects of theories which break down arbitrary distinctions between the social and the technical spheres, and considers that they open up new possibilities for those who want to understand the place of technology in human experience. However, he goes on to criticize the "almost total disregard" of the social constructivists "for the social consequences of technical choice." He echoes some of the previously articulated concerns on social structure, but with a moral and political emphasis, in the following passage: 
Social constructivism seems not to have noticed the problem of elitism, the ways in which even a broad, multicentred spectrum of technical possibilities is skewed in ways that favour certain social interests while excluding others....Although it succeeds in finding contingency rather than necessity in the course of technological change, it seems so far to have little to say about the deep-seated political biases that can underlie the spectrum of choices that surface for relevant social actors. [Winner 1993, p. 370]

Bijker (1993) responds directly to the critique of Winner by arguing that an amoral stance is not a necessity of the social constructivist approach. The paper appeals to researchers in science and technology studies to be concerned with its implications for society. The paper briefly indicates some directions for this, such as ethical studies and ethnoaccounting studies, designed to show interpretive flexibility, to suggest alternative technological choices, and thus to "debunk the socio-technical ensembles constructed by the powerful." Bijker does admit that "not many of our studies have been presented with this explicit aim."

Perhaps the best defense against the charge of amorality then is to produce studies that demonstrate an ability to carry out what Bijker suggests, and the paper by Star (1991) can be thought to provide one. She uses the example of her own allergy to onions and the indifference to it of outlets in the McDonalds food chain to illustrate how the networks of the powerful can discriminate against various disadvantaged groups. She generalizes this experience as follows:

A stabilised network is only stable for some, and that is for those who are members of the community of practice who form/use/maintain it. Any part of the public stability of a standardised network often involves the private suffering of those who are not standard - who must use the standardised network, but who are also non-members of the community of practice. [Star 1991, p. 43]

A further example of a paper using the concepts of actor-network theory to make points that are certainly not amoral or apolitical is the paper by Boland and Schultze, cited earlier, where they explicitly examine the political and moral agendas and networks of the proponents of activity based costing. Similarly, Monteiro and Hanseth deliberately engage with the political implications of the EDI standards which they have investigated.

Despite the above examples, the charges of an amoral stance continue to be aimed at actor-network theory, and Latour (1991, p. 130) responds as follows:

Finally, we are left with the accusation of immorality, apoliticism, or moral relativism. Refusing to explain the closure of a controversy by its consequences does not mean that we are indifferent to the possibility of judgement, but only that we refuse to accept judgements that transcend the situation....Domination is an effect not cause. In order to make a diagnosis or a decision about the absurdity, the danger, the amorality, or the unrealism of an innovation, one must first describe the network. 
There is no problem here with "first describing the network" but what comes after this? Where do the moral judgements come from if not from ideas that transcend the situation? If the Internet is examined, we do not need actor-network theory to tell us that the African continent is almost totally excluded. We cannot make a moral judgement on this on the basis of the network alone, but need political and ethical theories concerning socio-economic development.

So, what is the conclusion here for IS researchers who wish to use their studies to examine ethical and moral implications related to information systems? The personal view of this author is that actor-network theory does not offer explicit help in this area. On the other hand, the use of the theory does not preclude such an analysis, as the studies cited above briefly illustrated. As in the previous sub-section, it is the exclusivity arguments of actor-network proponents that are most problematic; if these are ignored, Latour's suggestion that we should first describe the network is a valuable injunction. Moral and political issues should be debated from a solid empirical base, and actor-network theory offers a contribution to the latter if not directly to the former.

\section{3 the Problem of Generalized Symmetry}

We have already seen how the symmetric treatment for humans and nonhumans in actor-network theory has been the cause of considerable controversy. The description of both as actants rather than actors was thought by Collins and Yearley (1992b) to go some way toward eliminating this problem, but other writers express more serious reservations. For example, Pels (1995) notes that Latour's (1993) symmetric embrace includes science and politics, society and nature, in addition to humans and nonhumans. Pels has this to say in opposition:

Spokespersons may indeed symmetrically speak for both people and things, but only humans can act (can be permitted to act) as spokespersons. Perhaps we moderns have gone way too far in digging epistemological fences between ourselves and the remainder of nature, between science and politics, and between facts and values. But in the century which is presently drawing to a close, we moderns have also gone way too far in erasing all such distinctions, in totally politicizing culture, science and society, in massively reducing other people to the status of things, and in degrading ourselves to killing beasts of prey. [Pels 1995, pp. 138-139]

It does not need much imagination to see the type of things to which Pels is referring, such as IT-enabled modern warfare. Less dramatically, but arguably of even greater potential impact, is the IT-based vision of the virtual organization where an objective central group controls the company's global operations, moving people, jobs and societies like pawns on a chessboard (e.g., Mowshowitz 1994). Pels argues in favor of weaker asymmetries, retaining some crucial analytical distinctions between humans and nonhumans for example, and he considers that Latour's contribution is 
to provide an extreme position, which he does not agree with, but which forces us to rethink these issues.

Where does this philosophical debate leave the IS researcher? This author has found it valuable to think of things as actants and to consider whose interests they inscribe, represent, and speak for. This is not the same as assuming a symmetric position for people and things, but rather can be considered to be a valuable analytical device. The challenge of actor-network theory to the rigid separation of humans and nonhumans is a very valuable one in this age of hybrids and blurred and negotiable boundaries, but this does not imply an acceptance of the extreme position of symmetry.

\subsection{Problems of Description}

This last category of criticism concerns the major problem of description that arises from a study which follows the methodological guidelines of actor-network theory. It can be considered to be a rather more mundane issue than those discussed above, and there has been no great debate between critics and proponents. Nevertheless, we have noted it before in referring to limitations of some of the paper-length IS applications that used the theory. The problem is that such studies produce a veritable mass of detail, and the response of Latour, among others, is to produce book-length output (e.g., Latour 1996a). Even with this approach, Latour (1996b) is aware of problems. He discusses the limitations of trying to identify all of the heterogeneous associations between the human and nonhuman actors in the network. Instead, he proposes that one should examine the networks by tracing how an indefinite number of entities grasp one another in a limited number of ways. He illustrates this idea (1996b) with an amusing example of Anglo-French cooperation.

What advice can be offered to the IS researcher in this domain? In one sense, the problem is not particular to studies based on actor-network theory, but relates to any in-depth IS case study. However, the theory emphasizes the importance of detail, and thus the problem of selection for presentational purposes tends to be magnified. Three observations may provide a useful starting point for future work. First, it is noticeable that the IS field is singularly lacking in research-based books, rather than articles, and studies based on actor-network theory could offer a contribution here. Of course, many of the disciplinary mechanisms of tenure and promotion ascribe small value to books in relative terms, and individuals are not immune to these pressures. Nevertheless, the disciplinary mechanisms themselves are social constructions and thus not immutable. A second observation is that it would be desirable for IS journal editors to exercise discretion on paper length, and to allow the possibility for longer papers where they were based on in-depth case studies. Finally, we need to experiment with different ways to describe case studies in paper-length format; Latour's suggestion above is one possibility in this regard. 


\section{FUTURE PROSPECTS FOR THE THEORY IN IS RESEARCH}

Actor-network theory has not arisen by chance at this particular point in history, but instead represents an attempt to address the increasingly complex socio-technical world in which we live. Hybrids of human and nonhuman elements continue to proliferate, and the boundaries between the technical and the social, and between human and machine capabilities, are frequently contested and always negotiable. IS research should be centrally concerned with these areas, and the primary conclusion of this paper is that actor-network theory has much to offer the IS researcher in both theoretical and methodological terms. Concepts such as those in outlined in Table 1, and their linking within the broader philosophy of the theory, provide a valuable analytical tool, as the IS studies reported in section 3 illustrated. A further point to note with respect to these studies is that they covered a wide range of contexts, including the health sector, transport applications and government administration; and a considerable variety of information system types, including accounting systems, plant categorization systems and GIS. No particular context or information system type can be excluded as a possible application area for the theory.

Authors such as Latour have described applications of the actor-network approach where the theory was used as a basis throughout the research work, encompassing methodology, method, data collection, analysis and write-up (e.g. Latour 1996a). However, it is noticeable that the authors of the IS studies reported earlier, while they all used the theory for analytical purposes, did not normally appear to use it as the basis for their field research. Does this represent a failing on their part? The view of this author is that it does not, since if actor-network theory can be used to illuminate the results from field research, that is sufficient justification for its inclusion in published work. Nevertheless, there must be concern that, if the full conceptual apparatus of the theory is not applied during the field research, important aspects and processes may not have been studied and documented. The implication in this author's view is that it would be valuable to see some full applications of the theory in the IS area in the future, so that we are able to assess the additional benefits which may be derived from this approach.

What of the criticisms of the theory which we discussed at some length in the previous section? None of the conclusions that we reached prohibit the use of the theory in the IS field, but they do suggest some cautions or qualifications to the IS researcher. The theory can be complemented by other social theories which take better account of broader social structures, such as the work of Giddens. Moral issues are not a direct focus of actor-network theory, and thus an IS researcher addressing such issues may find the theory valuable for empirical purposes, but will need to draw from other areas to supplement the theory. With respect to the two other criticisms discussed earlier, the conclusions can be summarized that we do not have to accept the full symmetry hypothesis of humans and nonhumans in order to make use of the theory, and that the problems of writing up indepth case studies based on the theory 
are not unique to actor-network theory, but that we need further experimentation here to improve our ways of reporting such studies.

A final word on actor-network theory relates to the more general point of the role of theory in IS research, particularly in the increasing body of work which can be broadly labeled interpretive studies. This author still encounters requests from reviewers and editors for justification as to why a particular theory was the best one to use for a given study. There is not, and never will be, a best theory. Theory is our chronically inadequate attempt to come to terms with the infinite complexity of the real world. Our quest should be for improved theory, not best theory, and for theory that is relevant to the issues of our time. Actor-network theory can be considered to satisfy both these criteria, and its use for a wide range of IS studies in the future offers considerable potential for increased understanding of the socio-technical systems which are the focus for IS research.

\section{REFERENCES}

Bijker, W. E. (1993). "Do Not Despair: There is Life after Constructivism." Science, Technology and Human Values, Volume 18, Number 1, pp. 113-138.

Bijker, W. E.; Hughes, T. P.; and Pinch, T. J. (Editors) (1987). The Social Construction of Technological Systems. Cambridge, Massachusetts: MIT Press.

Bloomfield, B. P.; Coombs, R.; Cooper, D. J.; and Rea, D. (1992). "Machines and Manoeuvres: Responsibility Accounting and the Construction of Hospital Information Systems." Accounting, Management and Information Technologies, Volume 2, Number 4, pp. 197-219.

Bloomfield, B. P., and Vurdubakis, T. (1994). "Boundary Disputes: Negotiating the Boundary between the Technical and the Social in the Development of IT Systems." Information Technology and People, Volume 7, Number 1, pp. 9-24.

Boland, R. J., and Schultze, U. (1996). "From Work to Activity: Technology and the Narrative of Progress." In W. J. Orlikowski, G. Walsham, M. R. Jones, and J. I. DeGross (Editors), Information Technology and Changes in Organizational Work. London: Chapman \& Hall.

Bowers, J. (1992). “The Politics of Formalism." In M. Lea (Editor), Contexts of Computer-Mediated Communication. Hemel Hempstead, England: Harvester Wheatsheaf.

Bowker, G., and Star, S. L. (1994). "Knowledge and Information in International Information Management: Problems of Classification and Coding." In L. BudFrierman (Editor), Information Acumen: The Understanding and Use of Knowledge in Modern Business. London: Routledge.

Bowker, G.; Timmermans, S.; and Star, S. L. (1996). "Infrastructure and Organizational Transformations: Classifying Nurses' Work.” In W. J. Orlikowski, G. Walsham, M. R. Jones, and J. I. DeGross (Editors), Information Technology and Changes in Organizational Work. London: Chapman \& Hall. 
Callon, M. (1986). "Some Elements of a Sociology of Translation: Domestication of the Scallops and the Fishermen." In J. Law (Editor), Power, Action and Belief: A New Sociology of Knowledge? London: Routledge \& Kegan Paul.

Callon, M. (1991). "Techno-Economic Networks and Irreversibility." In J. Law (Editor), A Sociology of Monsters: Essays on Power, Technology and Domination. London: Routledge.

Callon, M., and Latour, B. (1992). "Don't Throw the Baby Out with the Bath School! A Reply to Collins and Yearley." In A. Pickering (Editor), Science as Practice and Culture. Chicago: University of Chicago Press.

Collins, H. M., and Yearley, S. (1992a). "Epistemological Chicken." In A. Pickering (Editor), Science as Practice and Culture. Chicago: University of Chicago Press.

Collins, H. M., and Yearley, S. (1992b). "Journey into Space." In A. Pickering (Editor), Science as Practice and Culture. Chicago: University of Chicago Press.

Giddens, A. (1984). The Constitution of Society. Cambridge, England: Polity Press.

Giddens, A. (1990). The Consequences of Modernity. Cambridge, England: Polity Press.

Giddens, A. (1991). Modernity and Self-Identity. Cambridge, England: Polity Press.

Habers, H. (1995). “Book Review: 'We Have Never Been Modern' by Bruno Latour." Science, Technology and Human Values, Volume 20, Number 2, pp. 270275.

Haraway, D. (1991). Simians, Cyborgs, and Women: The Reinvention of Nature. London: Free Association Books.

Hine, C. (1995). "Representations of Information Technology in Disciplinary Development: Disappearing Plants and Invisible Networks." Science, Technology and Human Values, Volume 20, Number 1, pp. 65-85.

Kavanagh, D., and Araujo, L. (1995). “Chronigami: Folding and Unfolding Time." Accounting, Management and Information Technologies, Volume 5, Number 2, pp. 103-121.

Latour, B. (1987). Science in Action: How to Follow Scientists and Engineers through Society. Cambridge, Massachusetts: Harvard University Press.

Latour, B. (1991). “Technology is Society Made Durable." In J. Law (Editor), A Sociology of Monsters: Essays on Power, Technology and Domination. London: Routledge.

Latour, B. (1993). We Have Never Been Modern. Hemel Hempstead, England: Harvester Wheatsheaf.

Latour, B. (1996a). Aramis or the Love of Technology. Cambridge, Massachusetts: Harvard University Press.

Latour, B. (1996b). "Social Theory and the Study of Computerized Work Sites." In W. J. Orlikowski, G. Walsham, M. R. Jones, and J. I. DeGross (Editors), Information Technology and Changes in Organizational Work. London: Chapman \& Hall.

Law, J. (1991). "Introduction: Monsters, Machines and Sociotechnical Relations." In J. Law (Editor), A Sociology of Monsters: Essays on Power, Technology and Domination. London: Routledge. 
Law, J. (1992). "Notes on the Theory of the Actor-Network: Ordering, Strategy and Heterogeneity." Systems Practice, Volume 5, Number 4, pp. 379-393.

Law, J. (1994). Organizing Modernity. Oxford: Basil Blackwell.

Monteiro, E., and Hanseth, O. (1996). "Social Shaping of Information Infrastructure: On Being Specific about the Technology." In W. J. Orlikowski, G. Walsham, M. R. Jones, and J. I. DeGross (Editors), Information Technology and Changes in Organizational Work. London: Chapman \& Hall.

Mowshowitz, A. (1994). "Virtual Organization: A Vision of Management in the Information Age." The Information Society, Volume 10, Number 4, pp. 267-288. Mumford, E. (1981). "Participative Systems Design: Structure and Method." Systems, Objectives, Solutions, Volume 1, pp. 5-19.

Orlikowski, W. J.;Walsham, G.; Jones, M. R.; and DeGross, J. I. (Editors) (1996). Information Technology and Changes in Organizational Work. London: Chapman \& Hall.

Pels, D. (1995). “Have We Never Been Modern? Towards a Demontage of Latour's Modern Constitution." History of the Human Sciences, Volume 8, Number 3, pp. 129-141.

Reed, M. I. (1995). "The Action/Structure Debate in Organizational Analysis." Conference on Structuration Theory and Organizations. Paris, France.

Star, S. L. (1991). "Power, Technologies and the Phenomenology of Conventions: On Being Allergic to Onions." In J. Law (Editor), A Sociology of Monsters: Essays on Power, Technology and Domination. London: Routledge.

Vidgen, R., and McMaster, T. (1996). "Black Boxes, Non-Human Stakeholders and the Translation of IT." In W. J. Orlikowski, G. Walsham, M. R. Jones, and J. I. DeGross (Editors), Information Technology and Changes in Organizational Work. London: Chapman \& Hall.

Walsham, G., and Sahay, S. (1996). "GIS for District-Level Administration in India: Problems and Opportunities." University of Lancaster Research Paper SM 02/96, Lancaster, United Kingdom.

Winner, L. (1993). "Upon Opening the Black Box and Finding it Empty: Social Constructivism and the Philosophy of Technology." Science, Technology and Human Values, Volume 18, Number 3, pp. 362-378.

\section{BIOGRAPHY}

Geoff Walsham is currently Acting Director of the MBA Programme at the Judge Institute of Management Studies, Cambridge University. His teaching and research is centered on the development, use and management of computer-based information systems, and the relationships of these systems to changes in organizations and societies. His last post was as Professor of Information Management at Lancaster University, but he returned to Cambridge in 1996, where he had previously worked for 19 years in the Management Studies Group of the Engineering Department. His publications include Interpreting Information Systems in Organizations (Wiley 1993) and Information Technology and Changes in Organizational Work (edited with W. Orlikowski, M. Jones and J. DeGross, Chapman \& Hall, 1996). 